\title{
Research Paper: The Effect of Combination Therapy; Man- ual Therapy and Exercise, in Patients With Non-Specific crossturk Chronic Neck Pain: A Randomized Clinical Trial
}

\author{
Maryam Ghodrati ${ }^{1}$ Zahra Mosallanezhad ${ }^{1,2^{*}}$, Mohsen Shati ${ }^{3}$, Forouzan Rastgar Koutenaei ${ }^{1}$, Mohammad Reza Nourbakhsh ${ }^{4}$, Mehdi Noroozi $^{5}$ \\ 1. Department of Physiotherapy, University of Social Welfare and Rehabilitation Sciences, Tehran, Iran. \\ 2. Iranian Research Center on Aging, University of Social Welfare and Rehabilitation Sciences, Tehran, Iran. \\ 3. Department of Ageing, Research Center on Aging, University of Social Welfare and Rehabilitation Sciences, Tehran, Iran. \\ 4. Department of Physical Therapy, University of North Georgia, Dahlonega, Georgia, United States. \\ 5. Substance Abuse and Dependence Research Center, University of Social Welfare and Rehabilitation Sciences, Tehran, Iran.
}

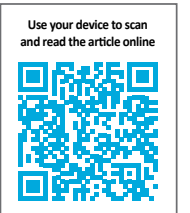

Cltwation: Ghodrati M, Mosallanezhad Z, Shati M, Rastgar Koutenaei F, Nourbakhsh MR, Noroozi M. The Effect of Combination Therapy; Manual Therapy and Exercise, in Patients With Non-Specific Chronic Neck Pain: A Randomized Clinical Trial. Physical Treatments. 2017; 7(2):113-121. http://dx.doi.org/10.32598/ptj.7.2.113

: http://dx.doi.org/10.32598/ptj.7.2.113

Article info:

Received: 19 Jan 2017

Accepted: 26 Apr 2017
Keywords:

Chronic neck pain, Manual therapy, Exercise therapy, Soft tissue release, Muscle energy techniques, Physiotherapy

\begin{abstract}
A B S T R A C T
Purpose: Neck pain is one of the most common health problems that its prevalence ranges from $34 \%$ to $50 \%$. Chronic Neck Pain (CNP) is also a frequent complaint in the general population. The pathogenesis of nonspecific CNP is not clear. This study aimed to assess the effects of soft tissue release, muscle energy techniques and exercise on neck Range of Motion (ROM), Neck Disability Index (NDI), and pain in patients with nonspecific CNP.
\end{abstract}

Methods: This is a randomized, single-blind, clinical study conducted on two groups of patients in Iran, during 2016-2017. Group A received intervention treatment and group B, as control, received no treatment for 21 days. Each group consisted of 12 participants who were selected considering inclusion and exclusion criteria. Each patient in group A received manual treatment protocols (soft tissue release and muscle energy techniques) plus exercise therapy, in six sessions, one session per day, two days a week over a period of 21 days. Clinical assessments were performed at the first and last session (before and after the treatment). Before starting the study, the reliabilities of measurement methods were evaluated and the results were acceptable. Clinical assessments included neck ROM, NDI and pain based on Visual Analogue Scale (VAS). Repeated measures ANOVA test was performed for data analysis using SPSS (version 20).

Results: Totally, 16 women and 8 men were participated in this study. To test the hypothesis and analysis of the study variables at regular intervals from the beginning to the end of treatment, repeated measures ANOVA was used. In the intervention group, the indexes showed significant improvements $(\mathrm{P}<0.001)$. This means that our intervention treatment was effective.

Conclusion: The study results support the effectiveness of the combination therapy (soft tissue release, muscle energy techniques plus exercise therapy) with some improvements in the neck ROM, NDI and pain (Based on VAS scores) for the management of patients with non-specific CNP.

\section{* Corresponding Author:}

Zahra Mosallanezhad, PT., PhD

Address: Department of Physiotherapy, University of Social Welfare and Rehabilitation Sciences, Tehran, Iran.

Phone: +98 (21) 22180039

E-mail:zmosallanezhad@yahoo.com 


\section{Introduction}

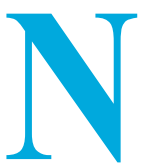

eck pain is a major problem for public health and its rate is steadily rising [1]. The prevalence of neck pain ranges from $34 \%$ to $50 \%$ [2-5]. The underlying causes of neck pain can be structural or functional disorders of the spine, muscles, ligaments, joints, or poor posture. However in most cases, the underlying pathophysiology of neck pain is unknown and as a result it is referred to "non-specific neck pain." Sometimes neck pain becomes chronic and incur a lot of cost and time to medical health system regarding its diagnosis and treatment process [68]. Also Chronic Neck Pain (CNP) may lead to absence from work and reduce the quality of life [9-11].

In most neck pains, no distinct underlying dysfunction or abnormal anatomical structure is found [12]. The prevalence of idiopathic neck pain is between $67 \%$ and $71 \%$ across studies; it has been shown that most people experience some neck pain during their lifetimes [13]. Although this problem is common and well-known, some patients cannot benefit from current treatments [14]. Studies have shown that this ailment is more prevalent in women than men $[15,16]$.

Overusing muscles in our body can cause some injuries. Our body usually responds to these injuries by producing scar tissue and adhesions. Furthermore, soft tissue disorders around the head and neck area can limit Range of Motion (ROM) of the neck and cause neck pain and muscle weakness [17]. Therefore, many treatment strategies are performed with the aim of restoring soft tissue function in patients with CNP [18].

There are some systematic study reviews on the treatment of neck pain by manual therapy [19-24]. In most of these studies, manual therapy is known as a non-invasive intervention for non-specific neck pain. Evidence-based treatments have compared the short- and long-term effects of combination therapy (manual therapy plus exercise) for the treatment of non-specific neck pain, along with using other therapies like electrotherapy, medication, acupuncture and patient education. According to these studies, combination therapy has been the most effective method so far. There are also evidence proving the short- and long-term effects of exercise therapy on neck pain and function $[12,25,26]$. Exercise programs differ with regard to intensity, duration, and frequency [27]. Studies revealed isometric exercises, neck stabilization exercises, and strength training (as a rehabilitation method) has positive effects on neck pain, reduce the pain and improve its function [28-30].
Studies have found that manual therapy techniques and exercise therapy applied to neck can temporarily relieve nonspecific CNP [31-35]. Given the inconclusive previous research results and the rising rate of neck pain [36], this study was designed to assess the effects of exercise and manual therapy on neck ROM and pain in patients with nonspecific CNP.

\section{Materials and Methods}

\section{Study design}

This is an experimental study and interventional clinical trial that is randomized and double-blind, performed in Tehran, Iran from 2016 to 2017. At first, we explained the study methods and procedure in detail to the volunteers. Then they signed the consent form and completed the general information questionnaire to help determining their eligibility status for the study. Participants were selected on the basis of inclusion and exclusion criteria of the study, then they were randomly assigned to one of the two groups A and B. The number of 12 participants were determined for each group. Each patient in group A received neck manual treatment protocols, including soft tissue release and muscle energy techniques plus exercise, in six sessions, one session per day, two days a week over a period of 21 days. Group B received no treatment for 21 days. However, after the completion of the study, they were received the study treatment, too. Clinical assessments were performed at the first and last session. Before starting the study, the reliability of measurement methods was evaluated and the results were acceptable. Clinical assessment tools were Visual Analogue Scale (VAS) for the intensity of pain, Neck Disability Index (NDI), and Range of neck Motion (ROM).

\section{Study population}

People with non-specific CNP who were referred to physical therapy clinic of the University of Social Welfare and Rehabilitation Sciences in Tehran, in 2017, participated in the study. Those patients with neurological disorders and acute muscle trauma were excluded Non-probability sampling method was used and grouping was randomly conducted. Participants based on the chronological order were divided into two groups of even or odd numbers.

\section{Data collection}

The participants were asked to rate their pain intensity by VAS, and complete NDI questionnaire. The active range of neck motion was measured by a goniometer 


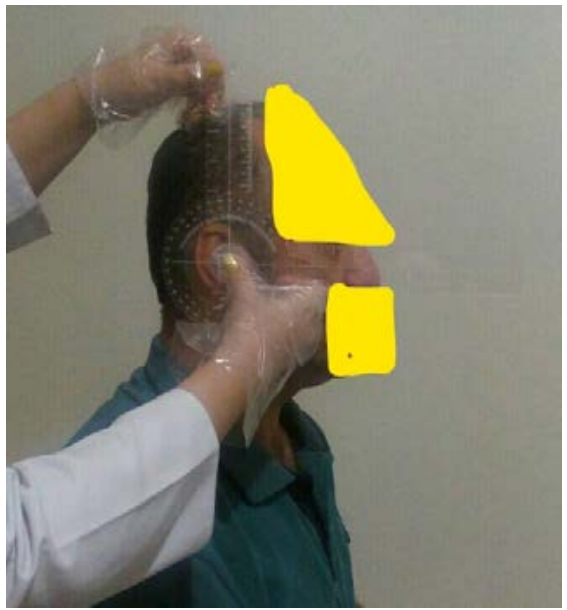

PHYSICAL TREATMENTS

Figure 1. Measuring cervical flexion and extension

The assessments for all patients were performed at the first and last session.

\section{Study instruments:}

\section{Demographic questionnaire}

Participants' age, sex, weight, height, marital status, medical history and medications, history of severe trauma on the neck and other relevant information were collected.

\section{Visual Analogue Scale}

The pain intensity was measured using VAS [37]. It was a graph from 0 to 10 ; patients determined their pain intensity scores between 0 and 10 . Zero represents no pain and 10 the most severe pain. So earning a higher score in this test means more pain intensity.

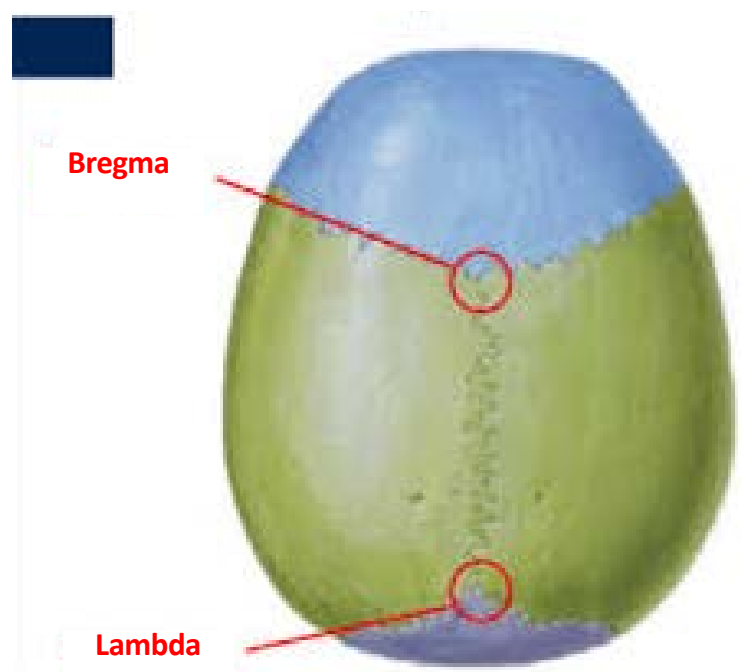

Figure 3. Measuring cervical rotation

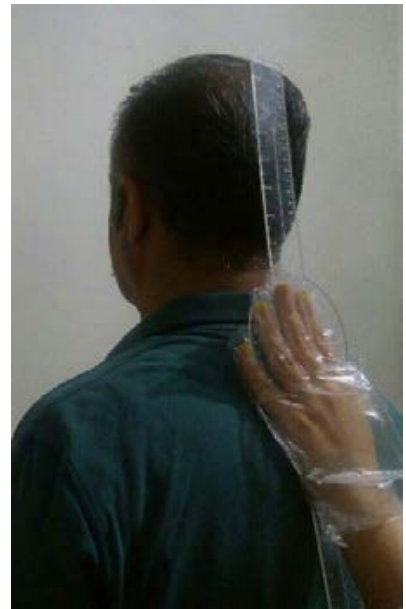

PHYSICAL TREATMENTS

Figure 2. Measuring cervical side bending

\section{Goniometer}

Range of neck motion was measured with a goniometer. After fixing the subject's shoulder, neck flexion, extension, right and left side bending, right and left rotation were measured.

We measured cervical flexion with chin tuck and extension with chin elevation. The goniometer axis was centered over the external acoustic meatus; the participant's fixed arm was held vertical, while his or her movable arm was aligned with the meatus-to-base of nares reference line as the patient actively flexed and extended the neck (Figure 1).

To assess cervical side bending, the goniometer axis was centered over the $\mathrm{C} 7$ spinous process; the fixed arm

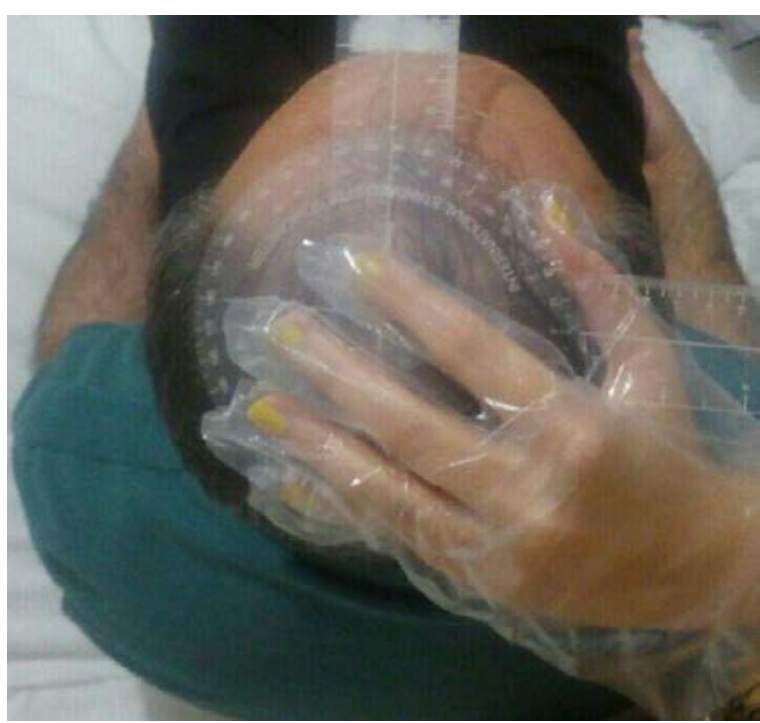

PHYSICAL TREA $\$ MENTS 

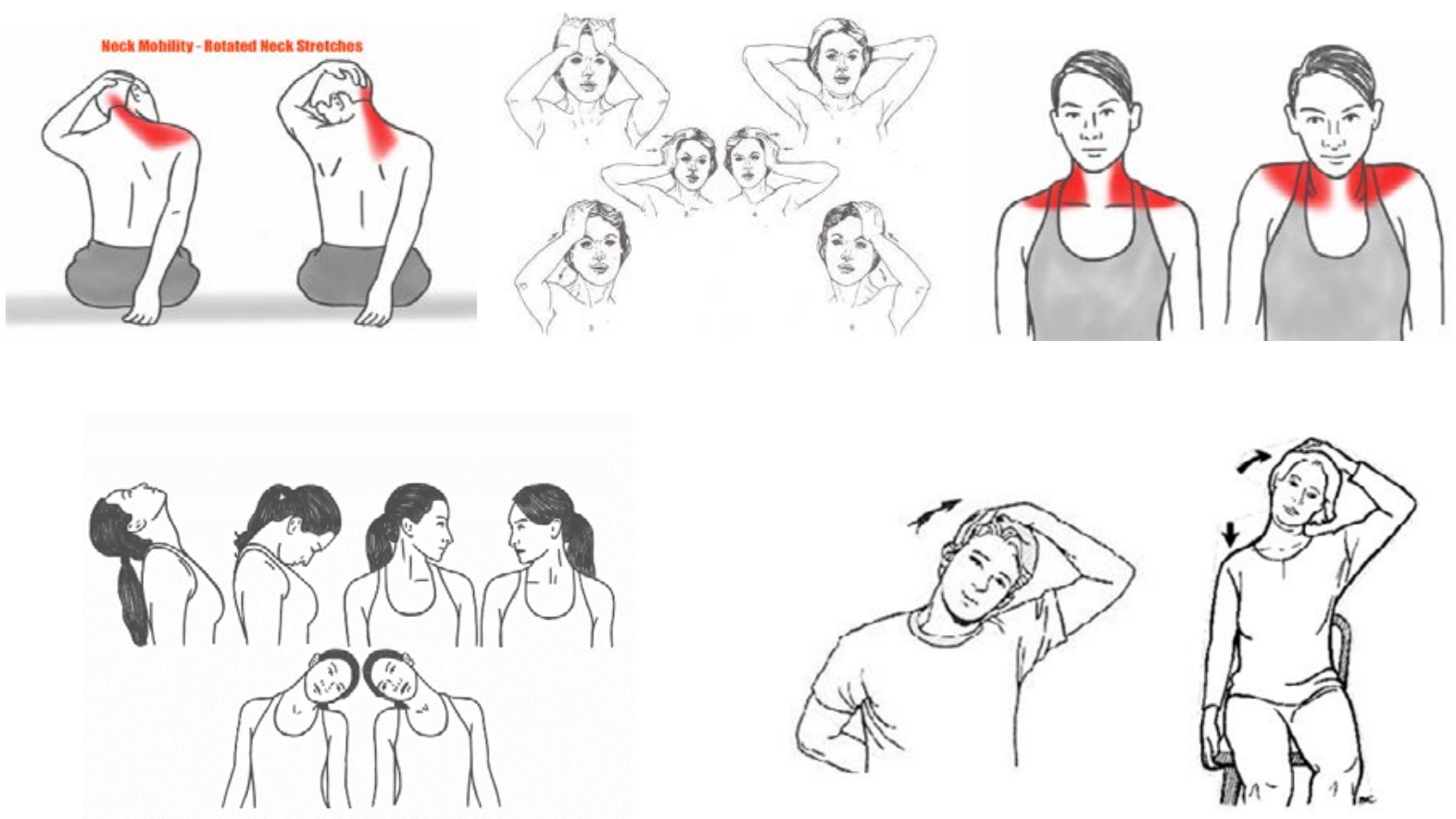

Figure 4. Prescribed exercises for neck

was held over spinous processes of thoracic vertebrae so that arm was perpendicular to ground, while the movable arm was aligned with dorsal midline of head. The reference point was the occipital protuberance (Figure 2).

We measured ROM of cervical rotation with placing the goniometer axis on the top of the subject's head; the midpoint between lambda (The point at which the two parietal and occipital bones meet) and bregma (The point at which the frontal bone and the two parietal bones meet) (Figure 3) [38].

\section{Neck Disability Index (NDI)}

This instrument can assess functional disability in patients with neck pain [39]. In this study, we used the Persian version of NDI [40]. The questionnaire was filled out by the patient in the first session and the last session.

\section{Treatment protocol}

\section{Muscle energy techniques}

Muscle energy technique is an advanced stretching technique. The muscle energy technique that we used was reciprocal inhibition, which is relaxing for short or stiff muscles. This technique was performed for 20 seconds and before repeating, we took the muscle to its new barrier [41]. Additionally, we performed both unilateral gross stretch and bilateral gross stretch of the upper trapezius [42]. Post-isometric relaxation is a very effective
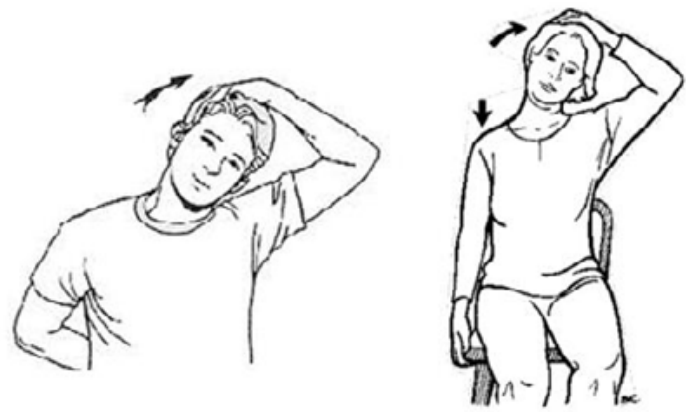

PHYSICAL TREA $\$ MENTS

method of dealing with tension in soft tissue problems. Post-isometric relaxation technique was applied to upper trapezius, sternocleidomastoid, suboccipital and levator scapulae muscles for 5 repetitions using $20 \%$ of maximal isometric contraction. Stretch was kept beyond resistance barrier for $20 \mathrm{~s}[41,43]$.

\section{Soft tissue release}

Active Release Technique (ART) is a kind of soft tissue technique [44]. Regarding the neck muscles, this technique involves a manual pressure being applied by therapist to a shortened muscle. The patient moved his or her head in a direction that elongate the muscle. During the movement, the therapist keeps tension over the muscle, as it slides out the therapist's fingers. This allows the therapists to feel the structure as it moves under the contact, which treats those restricted muscles, fascia, ligaments, or tendons [45]. Additionally, we performed both unilateral and bilateral gross stretch of the upper trapezius [42]. Also we applied muscle release technique for the suboccipital muscles, cross-hand release of the lateral neck, cross-hand release of the anterior cervical spine and post-isometric relaxation technique for the sternocleidomastoid [46].

\section{Exercise therapy}

In this study, prescribed exercises for neck included stretching, strengthening (repetitive, maximal resistance 
Table 1. Abbreviations of variables

\begin{tabular}{ccc}
\hline Variables & Abbreviations \\
\cline { 1 - 3 } Full Phrase & $\mathrm{NDI}$ \\
\cline { 1 - 2 } Neck Disability Index & VAS \\
\hline Visual Analogue Scale & RRot \\
\hline Right Rotation & LRot \\
\hline Left Rotation & RLF \\
\hline Right Lateral Flexion & LLF \\
\hline Left Lateral Flexion & PHYSICAL TREATMENTS
\end{tabular}

exercises), endurance (repetitive, submaximal resistance exercises), and ROM exercises [34, 47] (Figure 4).

\section{Ethical considerations}

The study was reviewed and approved by the Ethics Committee of the University of Social Welfare and Rehabilitation sciences, Tehran, Iran.

\section{Data analysis}

Statistical analysis was performed by using SPSS, version 24. Descriptive statistics such as average, range, standard deviation, percentage were calculated. Initially, a pilot study was conducted and the reliability of measurement methods was evaluated by determining Interclass Correlation Coefficients (ICC). Finally, using analysis of variance, we assessed the impact of changes in pain severity scores, NDI questionnaire and neck ROM. The abbreviations of variables are presented in Table 1.

\section{Results}

In total, 16 women and 8 men were participated in this study. The mean (SD) ages of the individuals participated in the control and intervention group were 30.58(9.66) and 33.08(9.94) years, respectively. Since people in each group were randomly assigned, we expect they were matched regarding demographic characteristics. Table 2 presents the results of baseline data comparison including age, weight, height, marital status and sex in the intervention and control group.

The ICCs regarding reliability assessment for both groups, consisting of 20 subjects with non-specific CNP and 20 healthy subjects are presented in Table 3, all values were found more than 0.90 .

\section{Analytic results}

In this part, the dependent variables such as the range of neck motion, NDI and VAS were discussed during the course of treatment between the two groups. Repeated measures ANOVA was used to test the hypothesis and analysis of study variables at regular intervals from the beginning to the end of treatment (Table 4). Intervention group showed significantly greater reduction in neck pain compared with the control group.

\section{Discussion}

\section{Overview of results}

Generally, it was determined that combination therapy (soft tissue release, muscle energy techniques, and exercise) for neck can improve the symptoms of pain, disability, and ROM in patients with non-specific CNP.

\section{Comparing the results with other studies}

There are various treatments available for patients with non-specific CNP [12]. Different medications can be used to treat neck pain. Many people try to relieve the pain with some painkillers like Non-Steroidal AntiInflammatory Drugs (NSAIDs), like ibuprofen or diclofenac. However, long-term use of these drugs is not suggested because of some side effects of these painkillers such as gastrointestinal bleeding or heart, kidneys, and liver problems [48]. In line with our results, a randomized study by Levoska and Keinänen-Kiukaanniemi (1993) showed that exercises and massage treatments three times a week over five weeks would reduce the occurrence of CNP [49].

Most previous studies have focused on manipulation and mobilization techniques, but in the present study, we 
Table 2. Baseline data comparison table

\begin{tabular}{|c|c|c|c|c|c|}
\hline Variable & Group & Min & Max & Mean & SD \\
\hline \multirow{3}{*}{ Age (y) } & Control & 18 & 50 & 30.58 & 9.66 \\
\hline & & & & & \\
\hline & Intervention & 19 & 49 & 33.08 & 9.94 \\
\hline \multirow{2}{*}{ Weight (kg) } & Control & 46 & 105 & 71.00 & 21.62 \\
\hline & Intervention & 53 & 94 & 72.08 & 15.48 \\
\hline \multirow{3}{*}{ Height $(\mathrm{cm})$} & Control & 156 & 183 & 168.67 & 8.77 \\
\hline & & & & & \\
\hline & Intervention 2 & 156 & 176 & 168.25 & 7.28 \\
\hline \multirow[t]{4}{*}{ Variable } & Group & Type & & No. & $\%$ \\
\hline & & Single & & 8 & 66.7 \\
\hline & Control & & & & \\
\hline & & Married & & 4 & 33.3 \\
\hline \multicolumn{6}{|l|}{ Marital status } \\
\hline & & Single & & 8 & 66.7 \\
\hline & Intervention & & & & \\
\hline & & Married & & 4 & 33.3 \\
\hline \multirow{7}{*}{ Sex } & & Female & & 7 & 43.8 \\
\hline & Control & & & & \\
\hline & & Male & & 5 & 62.5 \\
\hline & & & & & \\
\hline & & Female & & 9 & 56.3 \\
\hline & Intervention & & & & \\
\hline & & Male & & 3 & 37.5 \\
\hline
\end{tabular}

have focused on soft tissue release and muscle energy techniques. Since the role of the soft tissues and muscles in the neck area is very important, techniques that we used could be safer and more effective in the treatment of non-specific CNP [23, 31, 32].

Neck pain decreased after our treatment sessions in the intervention group. Many studies have suggested that strengthening exercises can improve CNP $[34,50]$. The intensity and type of exercise training suggested for neck pain, differ from study to study. The researchers usually prescribed exercises 2 to 5 times a week. Some studies suggest the strengthening exercises combined with stretching exercises or endurance training [48]. A study showed that the multimodal therapy (proprioceptive exercises, relaxation, and behavioral support) was more effective than exercises at home [7]. In consistent with our results, a systematic review study on manual thera-

Table 3. Relative reliability index for the studied variables

\begin{tabular}{ccc}
\hline & Variable & In Both Groups \\
\cline { 3 - 3 } & Flexion & ICC \\
\hline Extension & 0.99 \\
\hline RRot & 0.99 \\
\hline LRot & 0.98 \\
\hline RLF & 0.98 \\
\hline LLF & 0.99 \\
\hline
\end{tabular}


Table 4. Repeated measures ANOVA (pre-test and post-test)

\begin{tabular}{|ccc|}
\hline Variable & Levene's Test for Equality of Variances (P) & T-Test for Equality of Means (P) \\
\hline VAS difference & 0.106 & 0.000 \\
\hline NDI difference & 0.000 & 0.000 \\
\hline Flexion difference & 0.675 & 0.000 \\
\hline Extension difference & 0.134 & 0.000 \\
\hline LRot difference & 0.406 & 0.000 \\
\hline RRot difference & 0.063 & 0.000 \\
\hline LLF difference & 0.725 & 0.000 \\
\hline RLF difference & 0.346 & 0.000 \\
\hline
\end{tabular}

py and exercise for neck pain showed moderate quality evidence support for this combination therapy regarding pain reduction and improving quality of life over manual therapy alone for patients with CNP [51].

In a systematic review, the evidence suggests a moderate to high reliability of manual therapy in patients with chronic mechanical neck pain [52]. The long-term effects of exercise therapy in combination with other therapies, was greater than the effect of other manual therapy techniques alone [53].

According to our study, the improvement in disability was marked based on NDI in the intervention group. Although disability outcomes have been found to be similar after both manipulation and exercise, there may be additional benefits in combining these interventions [54]. In another study, the effect of neck stabilization exercises compared with isometric and stretching exercises in combination with physical therapy agents was studied. They have reported that neck stretching exercises improve the patient's disability [27]. In a study by Jari Ylinen et al. (2007), both stretching exercise and manual therapy considerably alleviated pain and disability in women with non-specific neck pain [55].

The other finding of present study is the improvement of neck ROM, in all directions including flexion, extension, right and left rotation, and right and left lateral flexion. According to a previous study, stabilization exercises with manual therapy may be better than stabilization exercises alone in improving disability, pain intensity and cervical rotation motion in patients with mechanical neck pain [37]. This finding was confirmed by other studies in which the group that received neck stretching exercises achieved a statistically significant increase in neck ROM [22].

Based on the present study results, combination therapy (soft tissue release, muscle energy techniques and exercise) have significant effects in patients with nonspecific CNP. This combination therapy increases ROM, and decreases NDI and pain in patients with nonspecific CNP. The examiner was not blinded in this study.

\section{Clinical implication}

This study assessed the effects of soft tissue release, muscle energy techniques and exercise, on ROM, NDI and pain in patients with nonspecific CNP and confirmed the efficacy of this combination therapy. This study offers an effective treatment protocol to patients and medical society, especially physiotherapists.

\section{Acknowledgments}

The authors gratefully acknowledge the participants. We also thank The University of Social Welfare and Rehabilitation Sciences for support. This research was reviewed and approved by the Research Ethics Committee of the University of Social Welfare and Rehabilitation sciences (USWR), Tehran, Iran.

\section{Conflict of Interest}

The authors declared no conflicts of interest. 


\section{References}

[1] Côté P, Cassidy JD, Carroll L. The treatment of neck and low back pain. Medical Care. 2001; 39(9):956-67. doi 10.1097/00005650-200109000-00006

[2] Bovim G, Schrader H, Sand T. Neck pain in the general population. Spine. 1994; 19(12):1307-9. doi: 10.1097/00007632199406000-00001

[3] Mäkela M, Heliövaara M, Sievers K, Impivaara O, Knekt P, Aromaa A. Prevalence, determinants, and consequences of chronic neck pain in Finland. American Journal of Epidemiology. 1991; 134(11):1356-67. doi: 10.1093/oxfordjournals. aje.a116038

[4] Barry M, Jenner JR. ABC of Rheumatology: Pain in neck, shoulder, and arm. BMJ. 1995; 310(6973):183-6. doi: 10.1136/ bmj.310.6973.183

[5] Leclerc A, Niedhammer I, Landre M-F, Ozguler A, Etore $\mathrm{P}$, Pietri Taleb F. One-year predictive factors for various aspects of neck disorders. Spine. 1999; 24(14):1455. doi 10.1097/00007632-199907150-00011

[6] Ehsani F, Mosallanezhad Z. Epidemiological study on neck pain in office workers in Semnan, risk factors and consequences. Physical Treatments. 2012; 1(1):17-21.

[7] Taimela S, Takala E-P, Asklöf T, Seppälä K, Parviainen S. Active treatment of chronic neck pain. Spine. 2000; 25(8):10217. doi: 10.1097/00007632-200004150-00018

[8] Hagberg M, Wegman DH. Prevalence rates and odds ratios of shoulder-neck diseases in different occupational groups. Occupational and Environmental Medicine. 1987; 44(9):60210. doi: $10.1136 /$ oem.44.9.602

[9] Westgaard RH, Jensen C, Hansen K. Individual and workrelated risk factors associated with symptoms of musculoskeletal complaints. International Archives of Occupational and Environmental Health. 1993; 64(6):405-13. doi: 10.1007/ bf00517946

[10] Daffner SD, Hilibrand AS, Hanscom BS, Brislin BT, Vaccaro AR, Albert TJ. Impact of neck and arm pain on overall health status. Spine. 2003; 28(17):2030-5. doi: 10.1097/01. brs.0000083325.27357.39

[11] Takala EP, Viikari Juntura E, Moneta GB, Saarenmaa K, Kaivanto $K$. Seasonal variation in neck and shoulder symptoms. Scandinavian Journal of Work, Environment \& Health. 1992; 18(4):257-61. doi: 10.5271/sjweh.1580

[12] Tsakitzidis G, Remmen R, Dankaerts W, Van Royen P. Non-specific neck pain and evidence-based practice. European Scientific Journal. 2013; 9(3).

[13] Fernández-de-las-Peñas C, Simons DG, Cuadrado ML Pareja JA. The role of myofascial trigger points in musculoskeletal pain syndromes of the head and neck. Current Pain and Headache Reports. 2007; 11(5):365-72. doi: 10.1007/ s11916-007-0219-z

[14] Catanzariti JF, Debuse T, Duquesnoy B. Chronic neck pain and masticatory dysfunction. Joint Bone Spine. 2005; 72(6):515-9. doi: 10.1016/j.jbspin.2004.10.007

[15] Fejer R, Kyvik KO, Hartvigsen J. The prevalence of neck pain in the world population: a systematic critical review of the literature. European Spine Journal. 2005; 15(6):834-48. doi: $10.1007 /$ s00586-004-0864-4

[16] Hoftun GB, Romundstad PR, Zwart JA, Rygg M. Chronic idiopathic pain in adolescence - high prevalence and disability: The young HUNT study 2008. Pain. 2011; 152(10):225966. doi: 10.1016/j.pain.2011.05.007

[17] Jull GA, Falla D, Vicenzino B, Hodges PW. The effect of therapeutic exercise on activation of the deep cervical flexor muscles in people with chronic neck pain. Manual Therapy. 2009; 14(6):696-701. doi: 10.1016/j.math.2009.05.004

[18] Kim JH, Lee HS, Park SW. Effects of the active release technique on pain and range of motion of patients with chronic neck pain. Journal of Physical Therapy Science. 2015; 27(8):2461-4. doi: 10.1589/jpts.27.2461

[19] Vernon H, Humphreys BK. Chronic mechanical neck pain in adults treated by manual therapy: A systematic review of change scores in randomized controlled trials of a single session. Journal of Manual \& Manipulative Therapy. 2008; 16(2):42E-52E. doi: 10.1179/jmt.2008.16.2.42e

[20] Gross AR1, Goldsmith C, Hoving JL, Haines T, Peloso P, Aker P, Santaguida P, Myers C; Cervical Overview Group. Conservative management of mechanical neck disorders: a systematic review. The Journal of Rheumatology. 34(5):1083102. PMID: 17295434

[21] Philadelphia Panel Members, Clinical Specialty Experts, Albright J, Allman R, Bonfiglio RP, Conill A, et al. Philadelphia panel evidence-based clinical practice guidelines on selected rehabilitation interventions for neck pain. Physical Therapy. 2001; 81:1701-17. doi: 10.1093/ptj/81.10.1701

[22] Gross A, Kay T, Kennedy C, Gasner D, Hurley L, Yardley $\mathrm{K}$, et al. Clinical practice guideline on the use of manipulation or mobilization in the treatment of adults with mechanical neck disorders. Manual Therapy. 2002; 7(4):193-205. doi: 10.1054/math.2002.0477

[23] Aker PD, Gross AR, Goldsmith CH, Peloso P. Conservative management of mechanical neck pain: systematic overview and meta-analysis. BMJ. 1996; 313(7068):1291-6. doi: 10.1136/bmj.313.7068.1291

[24] Hurwitz EL, Aker PD, Adams AH, Meeker WC, Shekelle PG. Manipulation and mobilization of the cervical spine. Spine. 1996; 21(15):1746-59. doi: 10.1097/00007632199608010-00007

[25] Sarigiovannis P, Hollins B. Effectiveness of manual therapy in the treatment of non-specific neck pain: A review. Physical Therapy Reviews. 2005; 10(1):35-50. doi: $10.1179 / 108331905 \times 43436$

[26] Gross A., Kay T, Hondras M, Goldsmith C, Haines T, Peloso $P$, et al. Manual therapy for mechanical neck disorders: A systematic review. Manual Therapy. 2002; 7(3):131-49. doi: 10.1054/math.2002.0465

[27] Dusunceli Y, Ozturk C, Atamaz F, Hepguler S, Durmaz B. Efficacy of neck stabilization exercises for neck pain: A randomized controlled study. Journal of Rehabilitation Medicine. 2009; 41(8):626-31. doi: 10.2340/16501977-0392

[28] Chiu TTW, Lam TH, Hedley AJ. A randomized controlled trial on the efficacy of exercise for patients with chronic neck pain. Spine. 2005; 30(1):E1-E7. doi: 10.1097/01. brs.0000149082.68262.b1 
[29] Andersen LL, KjÆr M, SØgaard K, Hansen L, Kryger AI, SjØgaard G. Effect of two contrasting types of physical exercise on chronic neck muscle pain. Arthritis \& Rheumatism. 2007; 59(1):84-91. doi: 10.1002/art.23256

[30] Sweeney T. Neck school: Cervicothoracic stabilization training. Occupational Medicine (Philadelphia, Pa.). 1992; $7(1): 43-54$

[31] Namvar H, Olyaei G, Attarbashi Moghadam B, Hosseinifar M. Effect of myofascial release technique on pain, disability, maximum isometric contraction of the extensor muscles, and pressure pain threshold in patients with chronic nonspecific neck pain: Double blinded randomized clinical trial. Health Sciences. 2016; 5(7S):500-6.

[32] Yadav H, Goyal M. Efficacy of muscle energy technique and deep neck flexors training in mechanical neck pain: A randomized clinical trial. International Journal of Therapies and Rehabilitation Research. 2015; 4(1):52. doi: 10.5455/ ijtrr.00000048

[33] Nagrale AV, Glynn P, Joshi A, Ramteke G. The efficacy of an integrated neuromuscular inhibition technique on upper trapezius trigger points in subjects with non-specific neck pain: a randomized controlled trial. Journal of Manual \& Manipulative Therapy. 2010; 18(1):37-43. doi: 10.1179/1066 98110x12595770849605

[34] Freburger JK, Carey TS, Holmes GM, Wallace AS, Castel LD, Darter JD, Jackman AM. Exercise prescription for chronic back or neck pain: Who prescribes it? Who gets it? What is prescribed?. Arthritis Care \& Research. 2009; 61(2):192-200. doi: 10.1002/art.24234.

[35] Hurwitz EL, Carragee EJ, van der Velde G, Carroll LJ, Nor$\operatorname{din}$ M, Guzman J, et al. Treatment of neck pain: Noninvasive interventions. Spine. 2008; 33(Supplement):S123-52. doi: $10.1097 /$ brs.0b013e3181644b1d

[36] Sarig Bahat $\mathrm{H}$. Evidence for exercise therapy in mechanical neck disorders. Manual Therapy. 2003; 8(1):10-20. doi: 10.1054/math.2002.0480

[37] Haefeli M, Elfering A. Pain assessment. European Spine Journal. 2005; 15(S1):S17-S24. doi: 10.1007/s00586-0051044-x

[38] Youdas JW, Carey JR, Garrett TR. Reliability of measurements of cervical spine range of motion-Comparison of three methods. Physical Therapy. 1991; 71(2):98-104. doi: 10.1093/ptj/71.2.98

[39] Tsakitzidis G, Remmen R, Peremans L, Van Royen P, Duchesnes C, Paulus D, et al. Non-specific neck pain: Diagnosis and treatment. Good Clinical Practice (GCP). KCE Reports C. $2009 ; 119$.

[40] Mousavi SJ, Parnianpour M, Montazeri A, Mehdian H, Karimi $\mathrm{A}$, Abedi $\mathrm{M}$, et al. Translation and validation study of the Iranian versions of the neck disability index and the neck pain and disability scale. Spine. 2007; 32(26):E825-31. doi: 10.1097/brs.0b013e31815ce6dd

[41] Chaitow L. Muscle energy techniques. Amsterdam: Elsevier Health Sciences; 2013.

[42] Manheim CJ. The myofascial release manual. Thorofare, NJ: Slack Incorporated; 2008.
[43] Phadke A, Bedekar N, Shyam A, Sancheti P. Effect of muscle energy technique and static stretching on pain and functional disability in patients with mechanical neck pain: A randomized controlled trial. Hong Kong Physiotherapy Journal. 2016; 35:5-11. doi: 10.1016/j.hkpj.2015.12.002

[44] Spina AA. External coxa saltans (snapping hip) treated with active release techniques ${ }^{\circledR}$ : A case report. The Journal of the Canadian Chiropractic Association. 2007; 51(1):23-9. PMCID: PMC1924651

[45] Feeney T. Active Release Techniques (ART) for neck pain or stiffness [Internet]. 2015 [Cited 2015 March 3]. Available from: http:// whitleybaychiropractic.co.uk/neck-pain-andstiff-neck-active-release-art/

[46] Stanborough M. Direct release myofascial technique: An illustrated guide for practitioners. London: Churchill Livingstone; 2004.

[47] Ylinen J. Physical exercises and functional rehabilitation for the management of chronic neck pain. Europa Medicophysica. 2007; 43(1):119-32. PMID: 17369784

[48] Informed Health Online. What are the treatment options for non-specific neck pain [Internet]. 2015 [Cited 2015 December 2]. Available from: https://www.ncbi.nlm.nih.gov/ pubmedhealth/PMH0084211/

[49] Levoska S, Keinänen Kiukaanniemi S. Active or passive physiotherapy for occupational cervicobrachial disorders? A comparison of two treatment methods with a 1-year follow-up. Archives of Physical Medicine and Rehabilitation. 1993; 74(4):425-30. PMID: 8466426

[50] Kay T, Santaguida P, Hoving J, Bronfort G, Goldsmith C. Exercises for mechanical neck disorders. The Cochrane Database of Systematic Reviews. 2003; doi: 10.1002/14651858. cd004250

[51] Miller J, Gross A, D'Sylva J, Burnie SJ, Goldsmith CH, Graham N, et al. Manual therapy and exercise for neck pain: A systematic review. Manual Therapy. 2010; 15(4):334-54. doi: 10.1016/j.math.2010.02.007

[52] Vernon H, Humphreys K, Hagino C. Chronic mechanical neck pain in adults treated by manual therapy: A systematic review of change scores in randomized clinical trials. Journal of Manipulative and Physiological Therapeutics. 2007; 30(3):215-27. doi: 10.1016/j.jmpt.2007.01.014

[53] Vincent K, Maigne JY, Fischhoff C, Lanlo O, Dagenais S. Systematic review of manual therapies for nonspecific neck pain. Joint Bone Spine. 2013; 80(5):508-15. doi: 10.1016/j.jbspin.2012.10.006

[54] Bronfort G, Evans R, Anderson AV, Svendsen KH, Bracha Y, Grimm RH. Spinal manipulation, medication, or home exercise with advice for acute and subacute neck pain: a randomized trial. Annals of internal medicine. 2012; 156(1 Part_1):1-10. doi: 10.7326/0003-4819-156-1-201201030-00002.

[55] Ylinen J, Wirén K, Häkkinen A. Stretching exercises vs manual therapy in treatment of chronic neck pain: A randomized, controlled cross-over trial . Journal of Rehabilitation Medicine. 2007; 39(2):126-32. doi: 10.2340/16501977-0015 